\title{
To clip, or not to clip? Prophylactic left atrial appendage ligation should be performed in patients with, or at risk for, atrial fibrillation
}

\author{
Andrew W. Shaffer, MD, MS, and Sara J. Shumway, MD
}

From the Division of Cardiothoracic Surgery, University of Minnesota, Minneapolis, Minn.

Disclosures: Authors have nothing to disclose with regard to commercial support.

Received for publication April 4, 2018; accepted for publication April 9, 2018; available ahead of print May 2, 2018.

Address for reprints: Sara J. Shumway, MD, 420 Delaware St SE, MMC 207, Minneapolis, MN 55455 (E-mail: shumw001@umn.edu).

J Thorac Cardiovasc Surg 2018;156:1069-70

$0022-5223 / \$ 36.00$

Copyright (c) 2018 by The American Association for Thoracic Surgery

https://doi.org/10.1016/j.jtcvs.2018.04.034

We applaud Ando and colleagues ${ }^{1}$ for their article in this issue of the Journal, "Concomitant Surgical Closure of Left Atrial Appendage: A Systematic Review and Meta-analysis." Their work aims to address the following clinical question: Is left atrial appendage closure (LAAC) a potential alternative to lifelong anticoagulation? Although the statistical results limit their ability to assertively say that LAAC can be used as an alternative to lifelong anticoagulation, they have compiled the strongest body of evidence for LAAC in elective cardiac surgical cases.

Atrial fibrillation is an onerous disease to live with, and $20 \%$ to $25 \%$ of people will have atrial fibrillation in their lifetimes. $^{2-4}$ Patients often have symptoms, with difficulty breathing, palpitations, limitations in stamina, and syncope. In addition, patients are instructed to take medications with high risks of inadvertent bleeding and other side effects. Reversal of warfarin coagulopathy in elderly patients with trauma is an actively researched area. ${ }^{5}$ Treatment of these patients is difficult and often results in poor outcomes. With novel anticoagulants coming to market, the treatment of patients being seen after trauma or for emergency surgery is growing in volume and complexity. As cardiac surgeons, we see patients for a short period along their cardiac health history. We, as surgeons, are in a powerful position to be able to address the burden of atrial fibrillation for patients who undergo cardiac surgery and potentially ease the burden of this disease as these patients age.

This meta-analysis by Ando and colleagues ${ }^{1}$ shows a statistically significant "better early survival and lower cerebral vascular accidents, especially in preoperatively AF [atrial fibrillation] cohorts." The combined follow-up period is relatively short; despite this brevity, the analysis shows a significant reduction in the clinical burden of atrial fibrillation for these patients. The difficult next step is determining which patients should be offered LAAC. There are

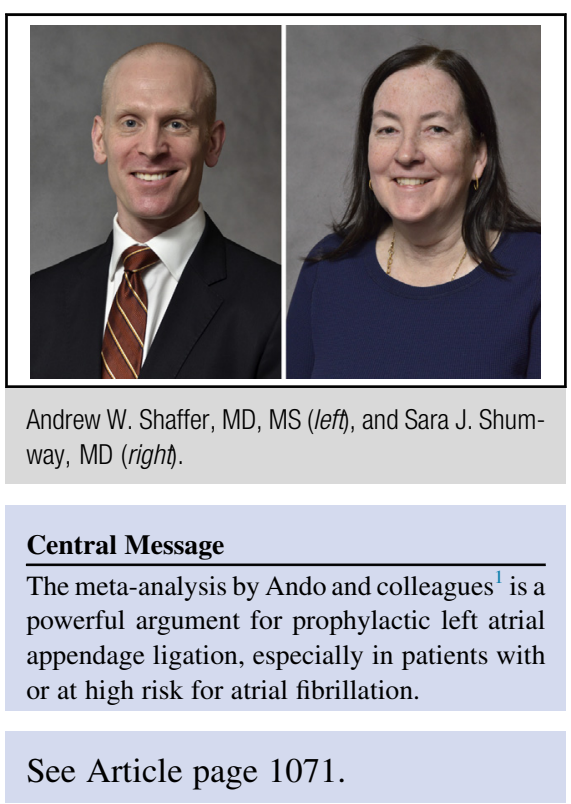

predictive models available. ${ }^{6}$ We propose consideration of the following attributes to help in this decision-making process:

- Age-patients older than 80 years will have higher risk of atrial fibrillation.

- History of atrial fibrillation-we believe that this group should undergo LAAC.

- Left atrial size-patients with enlarged atria $(>4 \mathrm{~cm})$ have a high risk of atrial fibrillation.

- Stroke-patients with previous strokes are at risk.

- History of falls - patients at high risk of injury should not take anticoagulation and would benefit from LAAC.

- History of bleeding - patients with intolerance to anticoagulation should undergo LAAC.

The article by Ando and colleagues ${ }^{1}$ is provocative when thinking about our everyday practice. Nearly $50 \%$ of our patients will have perioperative atrial fibrillation. These patients are arguably the ones at risk for further episodes of atrial fibrillation as they age. We should not neglect the opportunity during cardiac surgery to address the long-term stroke risk posed by atrial fibrillation. Conversely, we should not subject patients to undue risk (and expense) of LAAC. Ligation of the left atrial appendage can be performed easily with the traditional cut and sew method with relative ease and safety. Commercially available 
devices (AtriClip; AtriCure, Minneapolis, Minn) are easy to apply, fast, safe, and effective at left atrial appendage obliteration. There are new devices soon to be available with an easier application and a lower profile than those of the previous generation.

Again, we commend Ando and colleagues ${ }^{1}$ for their article, "Concomitant Surgical Closure of Left Atrial Appendage: A Systematic Review and Meta-Analysis." This article provides an excellent springboard for future study of the clinical utility of LAAC in routine cardiac surgery. Should we perform LAAC in all cardiac surgical cases? Probably not, but we should definitely do this for patients with history of atrial fibrillation, and probably for a select group of patients at high risk for atrial fibrillation in their lifetimes.

\section{References}

1. Ando M, Funamoto M, Cameron DE, Sundt TM III. Concomitant surgical closure of left atrial appendage: a systematic review and meta-analysis. J Thorac Cardiovasc Surg. 2018;156:1071-80.e2.

2. Mozaffarian D, Benjamin EJ, Go AS, Arnett DK, Blaha MJ, Cushman M, et al; American Heart Association Statistics Committee; Stroke Statistics Subcommittee. Heart disease and stroke statistics-2016 update: a report from the American Heart Association. Circulation. 2015;133:e38-360. Erratum in: Circulation. 2016;133:e599.

3. Lloyd-Jones DM, Wang TJ, Leip EP, Larson MG, Levy D, Vasan RS, et al. Lifetime risk for development of atrial fibrillation: the Framingham heart study. Circulation. 2004;110:1042-6.

4. Heeringa J, van der Kuip DA, Hofman A, Kors JA, van Herpen G, Stricker BH, et al. Prevalence, incidence and lifetime risk of atrial fibrillation: the Rotterdam study. Eur Heart J. 2006;27:949-53.

5. Ivascu FA, Janczyk RJ, Junn FS, Bair HA, Bendick PJ, Howells GA. Treatment of trauma patients with intracranial hemorrhage on preinjury warfarin. J Trauma. 2006;61:318-21.

6. Pollock BD, Filardo G, da Graca B, Phan TK, Ailawadi G, Thourani V, et al. Predicting new-onset post-coronary artery bypass atrial fibrillation with existing risk scores. Ann Thorac Surg. 2018;105:115-21. 